\title{
The Investigation of the Indoor Temperature During the Heat- Supplied Period and Its Influence in Winter in China
}

\author{
Linhai Wang ${ }^{1}$ and Zhao Liu $^{2 *}$ \\ ${ }^{1}$ Zhengzhou Foreign Language School, 450001Zhengzhou, Henan, China \\ ${ }^{2}$ Scholl of Economics, Henan University, 475001Kaifeng, Henan, China
}

\begin{abstract}
It is found that the heat-supplied temperature in winter is generally too high by investigating the heat-supplied samples in China. The excessively high temperature increases energy consumption, aggravates environmental pollution, and leads to frequent occurrence of diseases such as respiratory disease, cardiovascular and cerebrovascular disease. Therefore, it is suggested that the heat-supplied temperature should be controlled under $20^{\circ} \mathrm{C}$.
\end{abstract}

\section{Introduct}

Since the winter of 2012, there has appeared severe haze weather in North China and Huang-Huai area. In terms of spatial distribution, Beijing, Tianjin, Hebei, Shanxi, Shandong and Henan are the areas with the most serious haze. According to the air quality status of 74 cities released by the ministry of environmental protection, the top 10 cities with the worst air quality from 2013 to 2017 are all in the northern heating areas. According to the time distribution, the heating season in winter is the peak period of serious air pollution. According to the statistical yearbook of urban and rural construction 2017 released by the ministry of housing and urban-rural development, China's urban central heating area is 8.309 billion square meters, and heating energy consumption is equivalent to 164.2 million tons of standard coal, which will produce 432 million tons of carbon dioxide, 2.003 billion kilograms of sulfur dioxide, and 1.764 billion kilograms of nitrogen oxides. Therefore, it is of great importance to have a research on the heating temperature and its influence in China.

\section{Literature review}

A large number of empirical studies on the relationship between winter heating and local pollution have been conducted in China's academic circles. Most scholars have concluded that winter heating is a result of close and positive correlation with local pollution. Xu Ming and Xu Feng (2004) took Urumqi as a research sample and considered that the two pollutants PM10 and SO2 produced during heating in Urumqi had been the main cause of local air pollution [1]. Based on Harbin research samples, Huang Likun et al. (2011) conclude that pollutants such as TSP and PM10 exceeded the standard in winter and reached the national secondary standard in non-heating period [2]. Li Lan et al. (2013) took
Shenyang as a research sample, and believed that $50 \%$ of air pollution and $40 \%$ of total suspended particulates during coal heating came from coal burning. Coal burning during heating period has become the main cause of air pollution in Shenyang [3]. Li Linjia (2015) took Qingdao as a research sample to compare the smog weather conditions in different seasons. And he concluded that the carbon source metabolism level of air microbial community in the smog period is significantly higher than that in the non-smog period, and the carbon source metabolism intensity is higher, the metabolic type is richer [4]. Liang Yinshuang and Liu Liming (2015) took Beijing as a research sample and concluded that the SO2 in the heating season is generally higher than other seasons, and exhibits irregular changes at any time of the day within a week [5]. Chen Hangyu et al (2016) believe that due to coal-fired heating factors in Beijing, the number of special particles such as organic carbon and sulfur-containing particles in the particle size range of PM0.5 to 1 is about $28 \%$, but the increase is up to 145 times. In winter, the total number of particles below PM1 increased by as much as $700 \%$, and all carbonaceous particles increased significantly [6]. Xu Yanxian (2015) apply breakpoint regression and fixed effect models to compare the relationship between winter heating and local pollution in 29 cities in the north. It is believed that the deterioration of air quality during heating period is mainly caused by heating factors, and the lower the temperature, the higher the PM2.5, PM10 and SO2, CO, NO2 and other pollutants in the air numerically [7].

However, there is still lack of in-depth systematic investigation of indoor heating temperatures in China, and there is also lack of research on the influence of heating temperature on air pollution.

\section{Winter heating temperature Survey in China}

\footnotetext{
* Corresponding author: 1zh198511@,sohu.com
} 


\subsection{Survey samples}

A total of 300 valid samples were selected for this survey. According to the regional classification, the typical areas of central heating such as Henan, Beijing, Hebei, northwest and northeast, with large population and serious smog pollution in winter are selected. The structure of the sample area is shown in Figure1. Furthermore, according to the location, the sample includes urban houses $(55 \%)$, offices $(31 \%)$, other public places $(10 \%)$, and rural houses $(4 \%)$.

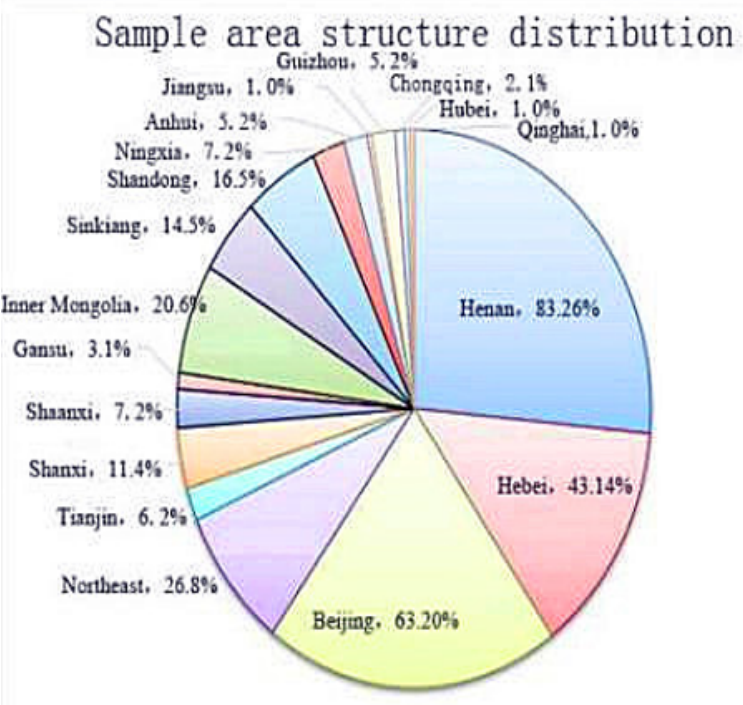

Fig1. Sample area structure distribution

\subsection{Survey data analysis}

\subsubsection{Analysis of heating temperature distribution}

A total of 300 valid samples were collected in this survey. The survey time was from 2016 to 2018 in winter and the effective data was 4,800. According to the arithmetic average algorithm, the average room temperature of the whole sample winter heating is $22.26^{\circ} \mathrm{C}$. If the rural sample data is deducted, the average temperature of the urban sample in winter is $22.48^{\circ} \mathrm{C}$.

The ratio of data below $16^{\circ} \mathrm{C}$ to total data is $1.72 \%$, the ratio of data at $16{ }^{\circ} \mathrm{C}$ (including $16{ }^{\circ} \mathrm{C}$ ) to $-20{ }^{\circ} \mathrm{C}$ is $13.21 \%$, and the ratio of data at $20{ }^{\circ} \mathrm{C}$ (including $20{ }^{\circ} \mathrm{C}$ ) to $-25{ }^{\circ} \mathrm{C}$ to total data is $65.07 \%$, and the ratio of data above $25^{\circ} \mathrm{C}$ to total data is $20.00 \%$.

\subsubsection{Analysis of district heating temperature}

The average room temperature in all regions of the country is $22.26^{\circ} \mathrm{C}$. The average room temperature from low to high is: $21.36^{\circ} \mathrm{C}$ in Henan, $21.45^{\circ} \mathrm{C}$ in Tianjin, $21.71^{\circ} \mathrm{C}$ in the northwest (Gan, Shan, Ning, Xin, Qing), $21.72^{\circ} \mathrm{C}$ in Shandong, $22.20^{\circ} \mathrm{C}$ in Shanxi, 22.74 ${ }^{\circ} \mathrm{C}$ in Hebei, $23.28^{\circ} \mathrm{C}$ in northeast (black, Ji, Liao), $23.46^{\circ} \mathrm{C}$ in Beijing, $24.55^{\circ} \mathrm{C}$ in Inner Mongolia , $24.89^{\circ} \mathrm{C}$ in southern region (Gui, $\mathrm{Yu}, \mathrm{Su}, \mathrm{Yu}$ ), of which the average room temperature in rural areas is $16.84^{\circ} \mathrm{C}$.

It can be seen that the winter heating temperature in rural areas is the lowest. In addition to the southern regions, the heating temperature in the cold regions in the north is the highest. For example, the average heating temperature in Inner Mongolia is the highest, higher than the average temperature of $2.29{ }^{\circ} \mathrm{C}$, and the northeast region is second only to Beijing, higher than the average heating temperature of $1.02{ }^{\circ} \mathrm{C}$.

\subsubsection{Analysis of location heating temperature}

The average temperature of urban houses is $22.44^{\circ} \mathrm{C}$, the average temperature of office is $22.16^{\circ} \mathrm{C}$, the average temperature of shopping malls is $23.23^{\circ} \mathrm{C}$, the average temperature of hotel is $24.28^{\circ} \mathrm{C}$, the average temperature of hospital is $23.94^{\circ} \mathrm{C}$, the average temperature of highspeed rail is $21.81^{\circ} \mathrm{C}$, and the average temperature of rural houses is $16.84^{\circ} \mathrm{C}$. It can be seen from the above data that the temperature of the hotel is the highest, followed by hospitals and shopping malls, and the temperature of rural houses is the lowest.

\subsubsection{Survey conclusions----the high temperature of urban heating is a common phenomenon.}

According to the heating standards stipulated in the Heating Management Regulations of various heating areas and cities, the indoor heating temperature standard determined in most areas of China is $16-20{ }^{\circ} \mathrm{C}$.

According to the sample data, the average room temperature in all regions of China is $22.26^{\circ} \mathrm{C}$, which is $6.26^{\circ} \mathrm{C}$ higher than the minimum standard of $16^{\circ} \mathrm{C}$ specified in most regions. Among them, residential houses (including rural houses) have an average room temperature of $22.06^{\circ} \mathrm{C}$, which is $6.06^{\circ} \mathrm{C}$ higher than the minimum standard temperature of $16^{\circ} \mathrm{C}$; the average room temperature of office is $22.16^{\circ} \mathrm{C}$, which is $6.16^{\circ} \mathrm{C}$ higher than the minimum standard temperature of $16^{\circ} \mathrm{C}$; the average room temperature of other public places is $23.59{ }^{\circ} \mathrm{C}, 7.59^{\circ} \mathrm{C}$ higher than the minimum standard temperature of $16^{\circ} \mathrm{C}$.

According to regional classification, the average temperatures in Henan, Beijing, Hebei (excluding rural areas), northwest, northeast, Shandong, Inner Mongolia, Shanxi and other northern regions were respectively $21.26{ }^{\circ} \mathrm{C}, 21.89{ }^{\circ} \mathrm{C}, 22.30{ }^{\circ} \mathrm{C}, 21.98{ }^{\circ} \mathrm{C}, 22.09{ }^{\circ} \mathrm{C}$, $21.29{ }^{\circ} \mathrm{C}, 22.24 .{ }^{\circ} \mathrm{C}, 21.91{ }^{\circ} \mathrm{C}$, respectively higher than the minimum standard of $5.26^{\circ} \mathrm{C}, 5.89^{\circ} \mathrm{C}, 6.30^{\circ} \mathrm{C}$, $5.98^{\circ} \mathrm{C}, 6.09^{\circ} \mathrm{C}, 5.29^{\circ} \mathrm{C}, 6.24^{\circ} \mathrm{C}, 5.91^{\circ} \mathrm{C}$.

From the above data analysis, the indoor temperature of urban buildings in the heating regions of northern China is obviously higher. Even in the sample data of rural households in rural areas, the ratio of indoor temperature exceeding the minimum standard of $16{ }^{\circ} \mathrm{C}$ is as high as $69.44 \%$, and only $30.56 \%$ of the sample data is lower than $16{ }^{\circ} \mathrm{C}$. 


\section{Study on the influence of excessive heating temperature}

\subsection{High heating temperature wastes lots of energy}

With the acceleration of urbanization, China's central heating area and energy consumption have shown a rapid increase trend. According to the statistics of the Urban and Rural Construction Statistical Yearbook of the Ministry of Urban and Rural Construction, from 2006 to 2017, the urban central heating area increased from 2.659 billion square meters to 8.309 billion square meters, an increase of 3.12 times, and the total heat supply increased from 215.805 million gigabytes (73.7 million tons of standard coal) to 368.285 million gigajoules (164.2 million tons of standard coal), an increase of 2.23 times. If coupled with decentralized heating in county towns and villages, energy consumption is much larger.

According to Zhang Wenting (2011) and Liu Meng et al. (2015), after the heating temperature reaches $16^{\circ} \mathrm{C}$ or above, the energy consumption increases by $5 \%-10 \%$ for every $1{ }^{\circ} \mathrm{C}$ increase in heating temperature $[8,9]$. According to the survey data, China's average heating temperature reached $22.26^{\circ} \mathrm{C}$, which is $6.26^{\circ} \mathrm{C}$ higher than $16^{\circ} \mathrm{C}$, the energy consumption will be $31.8 \%$ to $62.6 \%$ higher than the heating temperature of $16^{\circ} \mathrm{C}$. It can be seen that China's heating temperature is too high and consumes a lot of energy.

\subsection{High heating temperature is an important cause of environmental pollution in winter}

From the perspective of spatial distribution of environmental pollution, China's main polluted areas are concentrated in northern heating areas. From the perspective of time distribution, the winter heating season is a period of high pollution.

According to the relevant data of the "Real Gas Network" of the Ministry of Environmental Protection, we obtained the PM2.5 index chart between August 2016 and July 2017 in the main heating cities and non-heating cities in the south. It can be seen from the figure 2 that in the heating area in winter, PM2.5 showed a significant increase trend during the heating season in some major cities, and it dropped significantly during the non-heating season. In the hot summer and warm winters of Guangzhou, Xiamen, Nanning and other places, there is no obvious seasonal difference in the PM2.5 index, and the annual PM2.5 is within 60 . It can be comprehensively analysed that winter heating is an important reason for the formation of haze weather in the north.

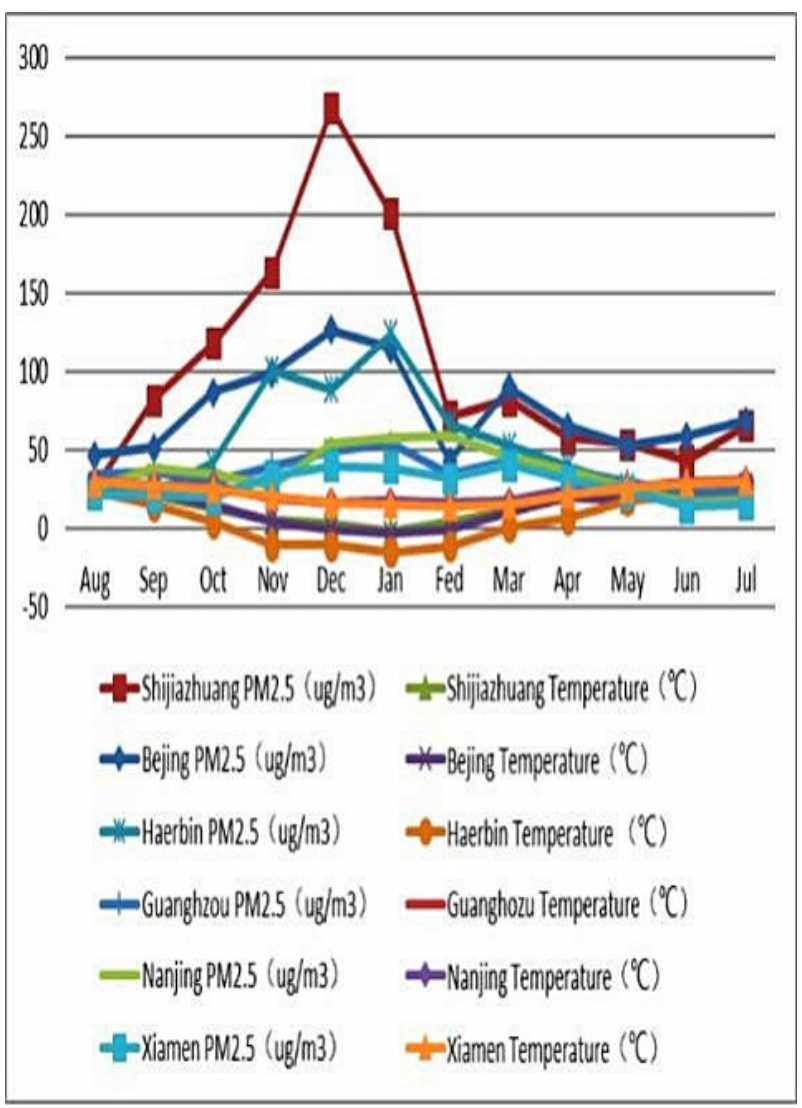

Figure 2 Outdoor Temperature and PM2.5 Chart of Some Major Cities

\subsection{High heating temperature is an important cause of seasonal diseases in winter.}

According to a study released by the World Health Organization, environmental air pollution in urban and rural areas (outdoor) is estimated to cause premature deaths of 3 million people worldwide in 2012. Chen et al. (2013) applied breakpoint regression to analyze the relationship between daily average TSP concentration and mortality in 90 cities in China from 1981 to 2000, and concluded that the life expectancy of residents in northern China decreased by 5.5 years due to pollution caused by heating in the north [10]. Excessive heating temperatures lead to increased air pollution, which is bound to increase the incidence of diseases such as respiratory, cardiovascular, blood, and reproductive systems.

\section{CONCLUSION}

Temperatures in winter in China are generally too high, which not only brings too much energy consumption, but also exacerbates air pollution and do harms to people's health. Therefore, it is suggested that the heating temperature in winter should be appropriately reduced and the current actual heating temperature should be controlled below $20^{\circ} \mathrm{C}$.

\section{References}

1. M. Xu, F. Xu, A. E. M. 18, 37 (2004) 
2. L.K. Huang, G.Z. Wang and K. wang Huang, E. E. J. 1, 146 (2011)

3. L. Li, E. Sci. Tech. J. 1, 152 (2013)

4. L.J. Li, Qd. Tech. Uni. D. (2015)

5. Y.S. Liang, L.M Liu, E. Sci. Tech. J. 12, 272 (2015)

6. Y.H Chen, J.G. Wang, S.P. Dong, E. E. J. 9, 5023(2016)

7. Y. Xu, Sd. Uni. D. (2015)

8. W.T. Zhang, Sw. Jt. Uni. D. (2011)

9. M Liu, K Xue, Y.Q Zhong, Civil E. E. J. 12, 204(2015).

10. Y.Chen, A. Ebenstein, M. Greenstone, H. Li, Proc. Natl. Acad. Sci. USA. J. 32, 110 (2013) 